\title{
O Cuidado e as Vivências de Internação em um Hospital Geral ${ }^{1}$
}

\author{
Tatiana Gomez Espinha ${ }^{2}$ \\ Uniararas \\ Mauro Martins Amatuzzi \\ Pontifícia Universidade Católica de Campinas
}

\begin{abstract}
RESUMO - Esta é uma pesquisa fenomenológica cujo objetivo foi compreender as vivências de internação em uma enfermaria de adultos de um hospital geral, com a finalidade de trazer elementos para uma discussão sobre o cuidado prestado a essas pessoas do ponto de vista psicológico. Foram realizadas entrevistas a partir da modalidade não-diretiva ativa e redigidas sob forma de narrativa. Os resultados encontrados indicam que: (1) a hospitalização deve ser compreendida enquanto processo; (2) a condição psicológica dos participantes interferiu em sua condição física; (3) os fatos objetivos não se mostraram tão importantes para a qualidade subjetiva da internação quanto o significado de sua vivência; (4) alguns relacionamentos estabelecidos pelos participantes, durante a internação, continham reciprocidade e outros não possuíam esse elemento; (5) os cuidados relacionados a regras e rotinas hospitalares foram recebidos de maneira diferente por cada participante. Existem poucos estudos que levem em consideração a vivência da hospitalização enquanto um processo e também a qualidade subjetiva da internação.
\end{abstract}

Palavras-chave: hospitalização; cuidado; abordagem centrada na pessoa; fenomenologia.

\section{Care and Internment Experiences in a General Hospital}

\begin{abstract}
This is a phenomenological research whose goal was to understand the internment experiences in an adult infirmary of a general hospital, in order to bring elements for a discussion about the psychological point of view of taking care of these people. The interviews were accomplished from an active, non-directive, modality and written under narrative form. The results indicate that: (1) hospitalization must be understood as a process; (2) the psychological condition of the participants interfered in their physical condition; (3) the objective facts were not as important for the internment subjective quality as the meaning of their experience; (4) some relationships established by the participants, during the internment, contained reciprocity and others did not have this element; and (5) care related to the hospital rules and routines was differently viewed by each participant. There are few studies that take into consideration the hospitalization experience like a process and also the internment subjective quality.
\end{abstract}

Keywords: hospitalization; care; approach centered in the person, phenomenology.

Apesar do convívio entre os profissionais do hospital e a pessoa internada ser intenso, e dos profissionais conhecerem algumas peculiaridades da experiência de internação, existem poucas pesquisas que dão voz à pessoa que vivencia o processo da hospitalização. Mesmo no campo da psicologia, há uma especificidade grande na área hospitalar: muitas vezes as pesquisas se referem à internação, mas no âmbito de uma determinada patologia, o que pode tirar o foco da pessoa. Por esse motivo, na presente pesquisa a atenção esteve voltada para as singularidades e diversidades da vivência da hospitalização simplesmente, não tendo como critério de inclusão dos participantes qualquer diagnóstico médico específico.

Mesmo existindo alguns procedimentos que podem amenizar ou intensificar um sofrimento ao longo da hospitalização, no decorrer das entrevistas com pessoas hospitalizadas, nada se mostrou mais importante do que a maneira como a pessoa vivencia essa situação. Por isso, o objetivo deste estudo foi compreender fenomenologicamente as vi-

1 Pesquisa derivada da Dissertação de Mestrado de Tatiana Gomez Espinha sob orientação de Mauro Martins Amatuzzi.

2 Endereço: Rua Sabiá, 75, Bairro Vale do Flamboyant. Atibaia, SP. CEP 12946-796.E-mail: tagomez8@hotmail.com. vências de estar internado em uma enfermaria de adultos de um hospital geral e a partir disso trazer elementos para uma discussão sobre o cuidado prestado a essas pessoas do ponto de vista psicológico.

Foram encontradas somente duas pesquisas que tratam desta experiência sob o ponto de vista da própria pessoa que a vivencia (Belatto, 2001; Graças, 1996) e mais algumas que se referem aos aspectos particulares desse processo: vivência de pessoas internadas com relação ao tempo, ao espaço, ao convívio com outras pessoas no hospital e às regras ou rotinas hospitalares (Chaves \& Ide, 1995; Sant'Anna, 2000; Toralles-Pereira, Sardenberg, Mendes \& Oliveira, 2004).

Bellato (2001) afirma que o tempo vivenciado pela pessoa hospitalizada é marcado pela freqüência das atividades desenvolvidas pelos profissionais que atuam na rotina do hospital, o que retira da pessoa doente sua temporalidade própria. Graças (1996) acrescenta que esse tempo é sentido de forma lenta e penosa. Esta lentidão, segundo a autora, é atenuada pela passividade a que as pessoas estão sujeitas. Quando não ocorrem acontecimentos agradáveis na rotina hospitalar, o tempo, na vivência do doente, provavelmente parece se prolongar.

No ambiente hospitalar, o corpo passa a ser transformado em espaço de atuação profissional dos membros da equipe de 
saúde (Bellato, 2001; Sant'Anna, 2000) por meio de procedimentos invasivos, dolorosos e constrangedores.

O espaço físico externo também é uma dimensão a ser discutida. Para Bellato (2001), o quarto de enfermaria, muitas vezes, apresenta pequenas proporções, principalmente quando comparado a outros lugares do convívio da pessoa em seu dia-a-dia. Em uma enfermaria também ocorre o convívio entre as pessoas adoecidas. Segundo Toralles-Pereira e cols. (2004), neste convívio apresenta-se a possibilidade de presenciar mais sofrimento e de perder a privacidade, mas, ao mesmo tempo, surge a alternativa de se construir um novo cotidiano e fazer novas amizades.

Com a hospitalização, há um vazio deixado pela separação de parentes e amigos. Poder contar com a presença desses pode representar uma ajuda no sentido de minimizar a angústia, a solidão e a insegurança, como afirma Graças (1996). Por outro lado, essa autora mostra também que as visitas são capazes de provocar sentimentos ambíguos nas pessoas internadas, pois ao mesmo tempo em que proporcionam bem-estar, quando terminam aumentam o vazio e a tristeza, estimulando o desejo de ir embora.

Graças (1996) registra ainda depoimentos que revelam a insatisfação referente às normas e rotinas organizacionais do hospital e a aspectos afetivos na interação e comunicação com a equipe. A imposição e a coerção estão presentes desde a opção pela internação até o momento da alta: a pessoa hospitalizada vivencia constantemente a impossibilidade de fazer suas próprias escolhas (Chaves \& Ide, 1995; Graças, 1996). No entanto, mesmo não podendo compreender e incorporar alguns dos novos hábitos do hospital, para ela desprovidos de qualquer significação, a pessoa internada cumpre essa nova rotina por mera obrigação (Graças 1996).

Embora nem sempre a pessoa hospitalizada seja considerada participante das decisões tomadas em relação a sua própria vida, e nem sempre compreenda essas decisões, segundo Toralles-Pereira e cols. (2004), ela se mantém como fonte viva de informações a serviço da equipe, o que caracteriza uma comunicação truncada. Segundo esses autores, a desinformação que a pessoa hospitalizada vivencia sobre sua condição, muitas vezes, pode acentuar a dependência em relação à equipe, favorecendo situações nem sempre necessárias de controle e dominação.

Em grande parte dessas pesquisas há uma ênfase nas relações vivenciadas durante a hospitalização: com a equipe de profissionais, com os companheiros de quarto e com os familiares. Essas relações podem, de fato, amenizar ou intensificar o sofrimento da pessoa internada. O relacionamento com os profissionais está intimamente ligado com o cuidado recebido pela equipe.

Diante do aqui exposto, este trabalho se apresenta como uma reflexão sobre cuidados psicológicos prestados num hospital, elaborada a partir do estudo de quatro casos diferentes de internação.

\section{Método}

A pesquisa fenomenológica, escolhida para desenvolver este estudo, encontra-se inserida em uma perspectiva de pesquisa qualitativa que, segundo Palmieri (2005), envolve a obtenção de dados descritivos, provenientes do contato direto do pesquisador com a situação estudada, preocupando-se mais com o processo do que com o produto, e enfatizando a perspectiva dos participantes e os significados por eles construídos. $\mathrm{Na}$ sua modalidade fenomenológica, visa captar o sentido que pode ter a vivência de uma pessoa em uma determinada situação (Forghieri, 2002), diante da questão trazida pelo pesquisador (Amatuzzi, 2001).

\section{Local}

A pesquisa foi desenvolvida em um Hospital Geral particular situado no interior do Estado de São Paulo. A população atendida pelo hospital é composta de clientes particulares e pessoas que têm convênio médico; não há atendimento pelo Sistema Único de Saúde. Na enfermaria de adultos, local em que a pesquisadora atua também como psicóloga profissional e onde foram realizadas as entrevistas, internam-se pessoas de diferentes diagnósticos médicos, tanto da clínica médica como da clínica cirúrgica.

\section{Participantes}

Por ser uma pesquisa de caráter exploratório, foram entrevistadas quatro pessoas adultas (três do sexo feminino e uma do sexo masculino). As idades variaram de 30 a 50 anos. Todos os participantes foram atendidos antes da entrevista ao menos uma vez pela psicólogapesquisadora. Foi a partir desses encontros que as pessoas foram convidadas a participar da pesquisa. Apesar de outras pessoas terem sido atendidas na época em que as entrevistas estavam sendo realizadas, por meio desses encontros, foi possível perceber que as pessoas selecionadas poderiam contribuir de maneira mais efetiva para o tema que estava sendo desenvolvido devido à riqueza de seus relatos.

O primeiro participante permaneceu no hospital por três meses devido a um câncer terminal, sendo que, em alguns momentos, ele tinha alta, mas logo voltava ao hospital. O segundo, depois de várias passagens pelo Pronto-Socorro, ficou internado dois dias devido à falta de ar. Já o terceiro ficou internado uma semana para fazer uma cirurgia na bexiga; no entanto, meses antes dessa internação, ele havia feito outra cirurgia, o que fez com que também ficasse internado. O último foi internado devido a sua terceira tentativa de suicídio, o que provocou complicações em seu pulmão e, com isso, ele permaneceu no hospital durante 15 dias.

$\mathrm{Na}$ época da internação, todos os participantes se encontravam afastados dos respectivos empregos, em decorrência do problema de saúde. Em virtude disso, todos vivenciavam uma condição de sofrimento físico e psicológico que já estava presente mesmo antes do período da internação. Todos os participantes tinham em comum esse histórico de sofrimento, o qual se prolongou, ao menos em parte, pelo período de hospitalização.

Com a autorização do diretor do Hospital para a pesquisa, o projeto foi submetido ao comitê de ética do Centro de Ciências da Vida da Pontifícia Universidade Católica de Campinas. 


\section{Procedimento}

Por meio das visitas de rotina, realizadas na enfermaria pela psicóloga-pesquisadora, foram encontrados os participantes. Todos foram atendidos por ela antes da entrevista. Depois do atendimento, a pessoa era convidada a participar da pesquisa. Nesse momento, deixava-se claro o objetivo do estudo. Quando elas concordavam em participar, marcava-se um horário para realizar a entrevista. Todos os participantes foram entrevistados no hospital, no momento em que eles se encontravam internados. Inicialmente, foi proposto que a entrevista fosse realizada na sala da psicóloga-pesquisadora, mas duas participantes preferiram permanecer na enfermaria.

No início da entrevista foram esclarecidas mais algumas dúvidas com relação à pesquisa e o termo de consentimento livre e esclarecido foi assinado. Dois dos participantes deixaram o hospital no mesmo dia e outros dois permaneceram hospitalizados por mais algum tempo; a psicóloga-pesquisadora continuou a oferecer seu acompanhamento psicológico para estes dois últimos participantes até o final da internação.

Seguiu-se o modelo de entrevista não-diretiva ativa proposto por Mucchielli (1991), pois a intenção foi proporcionar às pessoas internadas um momento de reflexão e de contato com suas vivências. Esse tipo de entrevista se assemelha à entrevista de ajuda, proposta por Rogers (1965/1977). Porém, Mucchielli acrescenta que, além do caráter da não-diretividade, também existe uma atitude ativa por parte do entrevistador.

Nesse tipo de entrevista não há um roteiro definido de questões, mas perguntas podem ser feitas no sentido de clarear a vivência relatada. Partiu-se da seguinte instrução disparadora: "Estou fazendo uma pesquisa sobre como a pessoa se sente quando está internada num hospital. Você pode me contar como é isso para você, como você se sente?".

Durante a entrevista, foi utilizado um gravador, sempre com o consentimento dos participantes. Com a ajuda da gravação, a pesquisadora construiu narrativas das entrevistas e dos outros encontros que teve com os participantes. A intenção da utilização da narrativa foi a de contar a experiência da pessoa hospitalizada não se atendo somente ao momento da entrevista e, nesse sentido, as narrativas foram construídas a partir da proposta de Benjamin (1937/1994).

\section{Análise das narrativas}

As narrativas foram analisadas pelo método fenomenológico, tendo como base a proposta feita por Amatuzzi (2003): (1) a partir da leitura cuidadosa de cada narrativa contendo a expressão do vivido proveniente da fala de cada participante, buscou-se o significado da vivência da hospitalização face ao problema da pesquisa; (2) foi feita uma síntese da vivência da hospitalização para cada participante; (3) partindo do conjunto de sínteses da vivência da hospitalização de cada participante, foi elaborada uma compreensão geral do vivido evidenciando os elementos comuns, indo além das particularidades de cada um; (4) com base nessa compreensão da vivência da hospitalização, finalmente, foi feita uma síntese da vivência de hospitalização, que consistiu em dispor em tópicos os principais pontos encontrados na compreensão.

\section{Resultados}

Foram apreendidos os seguintes tópicos a respeito da vivência da hospitalização:

- A hospitalização representou um processo: os participantes vivenciaram transformações durante sua estadia no hospital;

- As mudanças ocorridas (além daquelas diretamente relacionadas com o estado físico da pessoa) estavam ligadas ao estado de humor, aos sentimentos e aos relacionamentos vivenciados no hospital;

- A condição psicológica dos participantes interferiu em sua condição física e foi relevante para a qualidade da internação;

- Os fatos objetivos, como o longo ou breve tempo de internação, não se mostraram tão importantes para a qualidade subjetiva da internação como os significados construídos pela pessoa;

- Alguns relacionamentos vivenciados pelos participantes durante a internação tiveram reciprocidade psicológica e outros não;

- Relacionamentos sem reciprocidade nem sempre trouxeram sofrimento para o participante. Mas quando havia reciprocidade, ela promovia uma melhor qualidade da hospitalização;

- Os cuidados relacionados às regras e rotinas hospitalares foram recebidos de maneira diferente por cada participante: para alguns, eles favoreceram o bem-estar ao longo da internação, enquanto para outros, não;

- A vivência da hospitalização acarretou o desdobramento de sentidos do sofrimento anterior à internação.

\section{Discussão}

\section{Discutindo a vivência da hospitalização e o cuidado}

A vivência da hospitalização modificou-se durante a estadia na instituição para todos os participantes da pesquisa. Isso mostra que a hospitalização foi vivenciada como um processo e não como algo estático. Essa afirmação fica mais clara quando o comentário de Rogers (1961/1997) a respeito do processo terapêutico é considerado: "O processo da psicoterapia, tal como fomos apreendendo a partir da orientação centrada no cliente, é uma experiência única e dinâmica, diferente de indivíduo para indivíduo, mas patenteando uma lei e uma ordem espantosas na sua generalidade" (p. 86).

É claro que a hospitalização não equivale a um processo psicoterapêutico, embora possa ter algumas analogias com ele. Mas, nesse trecho, Rogers (1961/1997) destacou a singularidade da vivência de cada indivíduo e, ao mesmo tempo, uma ordem geral subjacente a essas múltiplas singularidades. Isso também pode ser aplicado ao caso da hospitalização. $\mathrm{O}$ significado de cada momento vivido pelos participantes no hospital foi se transformando ao longo da internação. Ama- 
tuzzi (1995), referindo-se também ao processo terapêutico, afirma: "Trata-se na verdade de um movimento" (p.65).

Graças (1996) expôs algumas mudanças vivenciadas pelos participantes de sua pesquisa no decorrer da passagem pelo hospital. Constatou que, no início, a internação parecia ser mais difícil devido ao impacto de uma situação não esperada. Entretanto, quando as pessoas começaram a compreender a extensão do comprometimento corporal e a necessidade da hospitalização, foram se tornando mais conformadas, encontrando algum sentido para sua permanência ali. A autora não teve a intenção de defender a experiência da hospitalização como um processo, mas ela menciona mudanças vivenciais ocorridas durante seu transcurso. Afirma ainda que essas mudanças são tão intensas que a hospitalização se torna um episódio marcante na vida das pessoas. A hospitalização como fato objetivo (estar internado no interior de um hospital como um doente) pode produzir mudanças subjetivas (vivência da hospitalização) marcantes na vida da pessoa.

É verdade que esses aspectos dinâmicos da vivência aplicam-se ao ser humano em qualquer situação ou à vida em geral. No caso da hospitalização, podemos especificar algumas dimensões comuns em que essas mudanças foram mais relevantes para os participantes da presente pesquisa. A princípio, a doença foi capaz de deflagrar um sofrimento presente desde antes da internação e a vivência da hospitalização acarretou um desdobramento de sentidos para esse sofrimento. Os significados para esse sofrimento não se mantiveram estáveis, pelo contrário, foram mudando de acordo com aquilo que era vivido no dia-a-dia do hospital.

Com isso, não há como desconsiderar aquilo que foi vivido no momento anterior à chegada no hospital: a historicidade da vida deve ser levada em conta quando se busca compreender a vivência da hospitalização. Graças (1996) indiretamente se refere a isso quando considera que internações anteriores, em seus participantes, influenciaram a aceitação das internações posteriores.

Foi possível perceber que os sentimentos dos participantes, do presente estudo, também se modificaram em diversos momentos da hospitalização. Na maioria das vezes, caminhavam juntos com o significado da vivência. O que aconteceu com uma das participantes desta nossa pesquisa ilustra o que queremos dizer. Quando ela estava doente e se via como um estorvo para seus familiares, sentia uma profunda tristeza e, mesmo na companhia deles, sentia-se sozinha. Com o passar dos dias, ela começou a se sentir melhor e pôde se relacionar de maneira mais livre com seus familiares, o que lhe trazia alegria e alívio de sua solidão. Essa mudança de sentimentos se refletiu, principalmente, nos relacionamentos. Estes não se mantiveram os mesmos do início até o final da internação, e isso aconteceu tanto em relação à família como à equipe de profissionais.

Ainda do ponto de vista psicológico, houve também uma alteração no estado de humor dos participantes. Para Forghieri (2007), o humor pode propiciar a experiência da nossa existência em termos de "subida" e "descida", e essas oscilações parecem estar muito presentes na vivência da hospitalização, variando desde sensação de bem-estar e contentamento até mal-estar e sentimento de contrariedade e angústia. Graças (1996) e Bellato (2001) também apontaram como freqüentes as alterações emocionais na fala dos participantes.

A dor pode interferir no estado de humor, aspecto comum e presente em diversos momentos da vivência da hospitalização, embora tenha sido possível perceber que não há como considerá-la somente por meio das sensações corporais. Graças (1996) ajuda a clarear essa afirmação, quando comenta que a experiência corporal é vivida numa totalidade unificada, o que significa que as dores do corpo parecem aderir-se à alma e, com isso, as sensações físicas ganham sentido para aquele que as vivencia.

Nesse sentido, a condição psicológica dos participantes mostrou-se intimamente ligada ao estado físico dos mesmos. Ao se sentirem bem psicologicamente, os participantes suportavam mais o sofrimento físico, ao passo que o mal-estar psicológico tornava a internação mais sofrida, independentemente de existir ou não a piora física. A dor, então, tem um significado que está em harmonia com o conjunto da vida; isso não quer dizer que a pessoa feliz não sinta dores, mas as suporta de maneira diferente (Van Den Berg, 1955/1973).

É possível pensar que a condição psicológica na qual o participante se encontrava tenha sido relevante para a qualidade de sua vivência de internação. Nesta pesquisa foi usada a expressão "qualidade de internação" com referência à vivência subjetiva de bem-estar ou mal-estar relacionada ao fato de estar hospitalizado. O bem-estar deve ser entendido enquanto sinônimo de satisfação e contentamento; o mal-estar, como sinônimo de angústia, constrangimento, inquietação e indisposição. Não foram encontradas pesquisas que mencionassem a qualidade subjetiva da internação, embora existam estudos com um enfoque quantitativo e que tratam dessa questão da qualidade de maneira objetiva (Gouvêa, Travassos \& Fernandes, 1997; Noronha, Machado \& Lima, 1996). Por exemplo, na pesquisa de Gouvêa e cols., a qualidade da assistência hospitalar foi mensurada a partir da taxa de mortalidade hospitalar e do número de óbitos evitáveis.

Os fatos objetivos não são tão relevantes quando se considera a qualidade subjetiva da internação; o que importa é como as pessoas vivenciam determinadas situações no decorrer da passagem pelo hospital. Isso pôde ser percebido no que diz respeito ao tempo, por exemplo. Quando é mencionado o tempo objetivo, há uma referência ao seu aspecto quantitativo, que pode ser mensurado por meio de horas, dias, meses etc. Entretanto, foi possível perceber que esse tempo objetivo de permanência no hospital não se mostrou relevante perante a condição de vida momentânea do participante: uma internação longa não esteve necessariamente relacionada com uma vivência penosa da internação. É possível encontrar uma idéia muito parecida na pesquisa realizada por Graças (1996) quando ela afirma que o movimento temporal mantém uma relação de sentido com os acontecimentos com os quais as pessoas estão envolvidas. Além disso, ela destaca que o tempo vivenciado é bem diferente do cronológico, objetivamente considerado, porém é um tempo próprio da consciência.

Por outro lado, as sensações de bem-estar e mal-estar podem interferir na vivência do tempo, já que, segundo Forghieri (2007), o fluxo do existir é experimentado de modo mais intenso e rápido nas vivências agradáveis e de maneira lenta e fraca nas desagradáveis. Isso pode ser percebido na 
vivência de outra participante de nossa pesquisa. Ao início de sua internação, quando ela estava se sentindo mal, emocional e fisicamente, a sua vontade era de ir embora o quanto antes. Mas, ao final, sua sensação de bem-estar era mais intensa, não se importando tanto em ficar mais alguns dias internada.

A maneira como os participantes vivenciavam seus relacionamentos também pode ter influenciado a qualidade da internação. Além disso, outro elemento que parece ter modificado essa qualidade foi a questão das mudanças que, frequentemente, ocorriam nos relacionamentos. Ao longo da hospitalização, os participantes vivenciaram diferentes relacionamentos, tanto com desconhecidos - outros internos e funcionários do hospital - como também com as pessoas que já faziam parte de sua vida, como é o caso dos familiares e amigos.

Os relacionamentos existentes na hospitalização carregavam consigo, em nossa pesquisa, um significado que era próprio de cada entrevistado. Com isso, a proposta de não se ater aos fatos objetivos, e sim à maneira como a pessoa vivencia seus relacionamentos, faz pensar que afirmação de Bellato (2001) e Graças (1996) em relação à importância da presença da família para assegurar o bem-estar da pessoa internada não tem ressonância com aquilo que foi encontrado neste nosso estudo. A presença da família não garantiu necessariamente o bem-estar dos participantes durante toda a internação e, até mesmo a ausência da família, para um dos participantes, foi capaz de deixá-lo mais tranqüilo.

Então, o que permeava os relacionamentos existentes ao longo da hospitalização dos participantes desta pesquisa? É possível afirmar que tenha sido a existência ou não de certa reciprocidade. Durante a internação, os participantes experimentaram relacionamentos em que ocorreu o elemento da reciprocidade e também outros, em que isso não aconteceu. Os relacionamentos em que não existia a reciprocidade nem sempre trouxeram sofrimento para o participante, porém, quando esse elemento estava presente, promoveu uma melhor qualidade da hospitalização.

Na perspectiva desta pesquisa, a reciprocidade foi considerada como uma qualidade intersubjetiva do relacionamento, e isso se torna mais claro com a definição mais objetiva do Novo Dicionário Aurélio da Língua Portuguesa (Ferreira, 2004), segundo a qual a reciprocidade se refere ao que implica em troca ou permuta. Em todo caso, é assim que Buber (1982) considera a reciprocidade: como fundamentalmente importante para se compreender a própria natureza humana. Segundo Forghieri (2007), as vivências que envolvem a reciprocidade e a responsabilidade também podem propiciar o desenvolvimento de nossas potencialidades, tais como a liberdade, a solidariedade, o amor e o altruísmo. E é possível relacionar isso com o cuidado em ambiente hospitalar, assim como será visto a seguir.

Nas duas pesquisas que tratam da questão da vivência da hospitalização, o único momento em que se tornava clara a presença da reciprocidade era no relacionamento existente entre as pessoas internadas. Graças (1996), autora de um dos estudos, comenta que a preocupação, o zelo, a compreensão e a ajuda são modos de ser na relação entre os internos. Já Bellato (2001), a autora do outro estudo, também cita a solidariedade e a compaixão existentes entre essas pessoas internadas.
Em contrapartida, em nossa pesquisa, os participantes não enfatizaram tanto em suas vivências o relacionamento entre internos, mas, quando isso aconteceu, foi possível perceber a presença da reciprocidade. Uma das participantes, ao conviver com o sofrimento de outros internados, abriu-se à possibilidade do relacionamento envolver a mutualidade ou a cumplicidade inerente à condição comum de se estar enfermo, o que foi valorizado.

Apesar das pesquisas de Bellato (2001) e Graças (1996) apontarem para a presença da reciprocidade somente no relacionamento entre internos, em nosso estudo, esse elemento esteve presente também nas relações com os familiares, embora isso não tivesse sido algo constante. Nos momentos em que a reciprocidade não existia, a visita dos familiares tornava-se incômoda e capaz de gerar angústia nos participantes, até porque eles não se sentiam compreendidos, já que a comunicação se tornava unilateral. Quando havia a mutualidade - participação afetiva e intersubjetiva de sentimentos - a presença da família passava a ser agradável e vista como fonte de segurança e amparo. Somente nesse sentido se torna possível afirmar que a presença da família pode oferecer bem-estar ao longo da hospitalização.

A relação com a equipe de profissionais, que inclui principalmente o pessoal da enfermagem e médicos, na maioria das vezes, não implicou em reciprocidade no sentido empregado aqui. Os relacionamentos eram baseados na função dos papéis, o que tornou a comunicação desigual, sem mutualidade. Mas, como não pensar em cuidado quando se traz à tona a questão do relacionamento entre pessoa hospitalizada e equipe de profissionais da saúde? É possível pensar que ambos (relacionamento e cuidado) caminham juntos.

Ao chegarem ao hospital, os participantes da pesquisa tinham vivenciado uma carência de cuidados e atenção enquanto estiveram doentes em suas casas. Essa ausência acontecia principalmente por parte da família e amigos. Mas, durante a hospitalização, eles experimentaram um tipo de cuidado que, até aquele momento, não tinham vivenciado: um cuidado voltado para o corpo doente e mais satisfatório do que aquele que acontecia na família ou entre amigos. Esse cuidado era vivenciado por meio da própria rotina hospitalar envolvendo procedimentos técnicos. Isso está afirmado também nas pesquisas de Bellato (2001) e Graças (1996). Para alguns participantes de nossa pesquisa, esse tipo de atenção recebida significou rigidez e cerceamento da liberdade; no entanto, para outros foi capaz de oferecer segurança e estabilidade. Dessa maneira, é possível pensar que os participantes não receberam da mesma maneira esses cuidados.

Em nossa pesquisa, as pessoas que não questionaram o cuidado transferiram para a equipe toda a responsabilidade de cura e recuperação do problema de saúde e, com isso, estiveram à mercê das decisões dos profissionais. Apesar de ter proporcionado um bem-estar para esses participantes, esse cuidado propiciou também certa alienação, deslocando a responsabilidade pessoal para a equipe de profissionais especializados. É interessante pensar que essa maneira de oferecer o cuidado, e até de se estabelecerem os relacionamentos dentro do hospital, está em consonância com aquilo que vivemos em nosso dia-a-dia, ou seja, essa dinâmica também está presente na ordem social maior, vigente em nosso meio. 
Dentro dessa perspectiva, Bellato (2001) percebeu em sua pesquisa que, para as pessoas hospitalizadas, os profissionais da saúde eram vistos como tendo um poder mágico de descobrir a doença e curar. Embora os participantes de seu estudo percebessem a incompetência de alguns profissionais, a autora afirma que as críticas eram feitas de maneira amena, como se as pessoas tivessem medo de atribuir responsabilidades àqueles considerados superiores. $\mathrm{O}$ medo da morte $\mathrm{e}$ da dor é tão extremo que leva a pessoa a se entregar às mãos daqueles que acredita terem competência e conhecimento. Essa situação de total conformismo, então, mostra bem a relação vertical que se estabelece nesses casos.

A situação trazida por Bellato (2001) parece ilustrar bem a vivência de um de nossos participantes, quando ele se entrega completamente aos cuidados médicos, sem questionar nenhum procedimento realizado. Mesmo não sendo correspondido em suas expectativas iniciais, ele continuou com a sensação de que aquelas pessoas da equipe eram especiais e sábias. Não há dúvida de que essas características da equipe transmitem certa segurança, porém não são suficientes, como aconteceu com outra de nossas participantes quando ela não se sentiu à vontade para recorrer aos profissionais no momento em que percebia ser necessário, alegando para si mesma que estaria atrapalhando se o fizesse.

Por parte da equipe técnica, é como se ficasse excluída a confiança na capacidade de crescimento do ser humano, já que o enfermo tende a ser considerado como inteiramente dependente dela para se recuperar. Do mesmo modo que a pessoa doente não confia no seu potencial, assim como foi possível perceber nas vivências de alguns de nossos participantes, o profissional também não acredita na capacidade dessa pessoa, e se estabelece, então, uma relação de dependência. Nessa relação, as pessoas se reduzem aos seus papéis - de doente e de profissional sendo o primeiro aquele que recebe e o segundo, o que dá. E, então, nessa relação não pode haver reciprocidade ou comunicação intersubjetiva.

A afirmação de que o profissional não confia na capacidade de crescimento das pessoas pode ser percebida, por exemplo, na maneira como são impostos os procedimentos às pessoas internadas sem admitir discussão. Isso pode ser confirmado também nas pesquisas de Bellato (2001), Graças (1996) e Toralles-Pereira e cols. (2004).

Há diferentes formas pelas quais as pessoas podem se colocar diante das outras, e as idéias de Buber (1982) podem ajudar, principalmente quando ele menciona a atitude de imposição. $\mathrm{O}$ autor acredita que essa postura não leva em consideração a pessoa no seu todo, mas somente uma de suas características, a que é importante para que o que se impõe atinja seu intento. Em oposição a isso, Buber citou a atitude de abertura, que proporciona ao outro acreditar em seu próprio potencial, o que leva ao desenvolvimento a partir de dentro de cada um.

Como já mencionado anteriormente, a atitude de imposição não gerou sofrimento para alguns participantes de nossa pesquisa, até porque eles não tinham consciência disso. Mas, para outros, esse tipo de cuidado gerou malestar e até desentendimentos entre eles e a equipe de profissionais, no que diz respeito à realização de procedimentos. Merighi (2002) pode ajudar a compreender melhor isso, quando diz que não basta o profissional incentivar a pessoa doente em determinado procedimento ou até mesmo julgar se ela é capaz ou não de fazer alguma coisa por si própria. A autora acredita que é primordial captar o sentido da vivência, deixando que a pessoa desvele seus anseios, pois a partir dessa atitude de abertura, ambos - profissional e cliente - poderão decidir o que há de melhor a ser feito em determinada situação.

Assim como afirmou Bellato (2001), pessoas que não se submeteram passivamente à manipulação do corpo e de sua vida, mesmo quando disseram claramente a sua insatisfação, continuaram não sendo ouvidas. A mesma autora ainda percebeu que essas pessoas acabam sendo vistas como "rebeldes", visto que não se submetem passivamente a uma situação, como se esperaria que fizessem. Isso pode ser confirmado pela situação complicada que se criou quando uma de nossas participantes não quis se submeter às normas e procedimentos do hospital. Ela se encontrava fisicamente muito debilitada e, mesmo assim, tinha dificuldades de receber um cuidado intensivo com algumas aparelhagens, pois isso lhe indicava que seu corpo estava cada vez mais debilitado.

Toralles-Pereira e cols. (2004) concluíram que a individualidade dos internos passou a ser um ruído no processo de comunicação entre estes e os profissionais de saúde. Em sua pesquisa, a equipe tendeu a silenciar o doente, e a comunicação passou a ser realizada em uma única direção, sem que houvesse espaço para o diálogo e para a participação do enfermo como um sujeito que sente, percebe e pensa sobre sua condição. É possível acrescentar ainda, com o apoio da reflexão de Bellato (2001), que o profissional da saúde, atualmente, tende a lidar com fatos concretos, deixando de lado a subjetividade da pessoa.

A competência técnica de médicos e enfermeiros que trabalham no hospital é sem dúvida importante. Mas há um outro âmbito de cuidado para além da questão técnica para o qual esta discussão chama a atenção. Isso parece se esclarecer na afirmação de Graças (1996): “ [...] as restrições feitas à enfermagem dizem respeito mais ao relacionamento e a atenção a eles (doentes) dispensados, do que à competência profissional, demonstrada ao prestar-lhes assistência" (p. 236). Assim como Valle e Françoso (1997) também afirmaram, é preciso aliar a competência técnica ao relacionamento humano, pois é somente por meio dele que se possibilita o verdadeiro cuidar.

Uma perspectiva unilateral aqui corre o risco de focalizar somente a doença e a eliminação de sintomas, o que descarta a pessoa em sua totalidade e complexidade. Como pôde ser visto nos participantes de nossa pesquisa, a questão da doença não se esgotava em si mesma, mas extravasava para uma condição de sofrimento existencial. Eles desejavam um tipo de cuidado que levasse em consideração suas particularidades e necessidades pessoais.

Acreditamos poder dizer que a doença de cada participante não se limitava somente ao corpo físico, mas carregava um significado, assim como destacam Valle e Françoso (1997). As autoras afirmaram ainda que não existe uma doença e um sujeito separados, mas sim, a pessoa que adoece, e esse adoecimento é vivido como uma experiência pessoal única, já que adquire um sentido específico no contexto de sua dinâmica. 
O sofrimento aqui mencionado não está preso aos sintomas físicos, como dores e desconforto, mas ele extrapola essa dimensão, apesar de não descartá-la. Assim, como salientam Pokladek e Haddad (2004), o corpo do doente deve ser visto em sua totalidade existencial e não como uma coisa impessoal e separada de sua historicidade. O sofrimento, então, parece acometer a pessoa nessa totalidade, sobre a qual discorrem os autores, e não em dimensões do ser humano de maneira separada.

Para ajudar a compreender melhor essa questão, recorreu-se às definições dos termos doença e enfermidade. Em português, essas duas palavras aparecem praticamente como sinônimos. Entretanto, pela etimologia, elas podem ser diferenciadas. A palavra "doença" vem do latim e é um termo relacionado com o verbo dolere que significa doer, sentir dor, sofrer (Houaiss, 2001). Já a palavra "enfermidade", que também vem do latim, é derivada de infirmitas e quer dizer fraqueza, debilidade, ou seja, sem firmeza. Talvez fique mais claro quando se recorre ao inglês, com a diferença entre illness e disease. No Dicionário Prático de Inglês (Michaelis, 2000), illness significa doença, indisposição, e disease corresponde à doença, enfermidade. Nessa busca, então, fica evidente que enfermidade aponta para o lado objetivo, físico, e doença tem um sentido mais subjetivo e psicológico, sendo esse o termo que mais se aproxima daquilo que vem sendo discutido neste estudo.

Por isso, é importante ao técnico ter para a si uma compreensão ampla do ser humano, já que é a partir desse olhar que irá surgir um determinado tipo de relacionamento e até mesmo um cuidado. De acordo com o que está sendo discutido neste momento, faz-se relevante recorrer à concepção de Rogers (1980/1983) sobre o conceito da tendência atualizante:

Podemos dizer que em cada organismo, não importa em que nivel, há um fluxo subjacente de movimento em direção à realização construtiva das possibilidades que lhe são inerentes. Há também nos seres humanos uma tendência natural a um desenvolvimento mais completo e mais complexo (p. 40).

Rogers (1980/1983) acreditava que essa propensão para o crescimento incluía o ser humano em sua totalidade e, não somente, em partes. Isso traz à tona a reflexão que a tendência atualizante também é importante porque abre caminho para o próprio funcionamento fisiológico dos órgãos no conjunto articulado do organismo. Com isso, ao promover a manifestação autêntica dessa disposição natural, pensando nas pessoas que se encontram doentes, é possível também facilitar o processo de recuperação da doença.

Ao tentar compreender tal manifestação nos seres humanos, é importante colocar de lado juízos e valores, pois o olhar deve ocorrer a partir do referencial de vida daquela pessoa, caso contrário, essa tendência poderá parecer sem sentido. Rogers (1965/1977) afirma que a tendência atualizante atinge aquilo que a pessoa percebe como valorizador ou enriquecedor, mas não necessariamente o que é valorizado objetivamente ao juízo dos outros.

$\mathrm{Na}$ área da saúde, essa concepção pode ajudar a compreender os significados que as pessoas atribuem a suas vivências, o que dá espaço para a construção de uma prática que tenha o ser humano como foco. Como foi apreendido que os significados se desdobram no decorrer da internação, também é relevante pensar que a pessoa deve ser considerada enquanto um ser em constante transformação e construção.

Nesse sentido, torna-se importante retomar o início desta discussão, quando foi considerado que a vivência da hospitalização deve ser compreendida enquanto um processo. Com essa afirmação, o cuidado prestado à pessoa hospitalizada também deve levar em conta as transformações ocorridas no período de internação. Principalmente do ponto de vista psicológico, é importante estar atento às rotulações e diagnósticos feitos à pessoa que está internada. Assim, a postura de Rogers (1965/1977) em relação ao diagnóstico em psicologia parece ser muito relevante. Para ele, esse só seria válido juntamente com uma compreensão do que se passa com a pessoa, tendo como referência seu próprio mundo interior de significado.

Pensar em categorias estanques e fechadas pode limitar o ser humano, desconsiderando sua capacidade de transformação e de crescimento. Essa questão ficou muito nítida na vivência de uma de nossas participantes, quando a equipe não conseguiu acompanhar suas mudanças e se ateve somente ao diagnóstico psiquiátrico. Com o acompanhamento das mudanças subjetivas, o profissional, de alguma maneira, transformar-se-ia, possibilitando uma reciprocidade intersubjetiva. Não havendo essa compreensão ou esse acompanhamento do fluxo subjetivo da pessoa, a relação só poderia ficar no plano técnico e objetivo e, portanto, seria limitada. Merleau-Ponty (1945/1999) chamou de modulação sincrônica essa transformação ocorrida mutuamente em um diálogo.

E como se torna possível tudo isso? Inicialmente, é imprescindível considerar a atitude de abertura proposta por Buber (1982), já discutida anteriormente, a qual se assemelha à atitude de aceitação incondicional proposta por Rogers (1980/1983). A importância dessa atitude se dá pelo fato de que, freqüentemente, dentro da área da saúde, está presente o avesso dessa postura, que Buber denominou de imposição. Tanto na pesquisa de Graças (1996) como na de Bellato (2001), que discutem a vivência da hospitalização, foi confirmada a imposição de regras e rotinas às pessoas internadas.

Outra questão essencial nesse tipo de cuidado e que aparece de maneira implícita ao longo desta discussão é a questão da compreensão empática mencionada por Rogers (1980/1983) e o conhecimento íntimo de Buber (1982). Eis o que diz Buber:

Tomar conhecimento íntimo de uma coisa ou de um ser significa, em geral, experienciá-lo como uma totalidade e, contudo, ao mesmo tempo, sem abstrações que o reduzam, experiênciá-lo em sua concretude (p. 147).

Esse olhar para o ser humano parece ser o inverso do que encontramos na área da saúde, quando se tem como referencial o modelo biomédico que reduz a pessoa à doença e aos sintomas.

Utilizando ainda as concepções de Buber (1982) e Rogers (1980/1983) para pensar a questão do cuidado, há também que se estar atento à pessoa do profissional de saúde. Ele pode estar presente na relação, sendo autêntico, sem agir sob 
uma aparência. No caso desses profissionais, a questão da aparência é muito presente, principalmente quando pensamos que as relações são desenvolvidas a partir da função dos papéis. Essa maneira de se relacionar distancia as pessoas e, com isso, não promove a reciprocidade. Para uma de nossas participantes, a figura do profissional era capaz de promover certa segurança, entretanto, ela não se sentia à vontade para recorrer a eles quando precisava. Desse modo, recorria aos companheiros de quarto, que estavam, naquele momento, mais parecidos e próximos.

\section{Considerações Finais}

Mas, o que é possível concluir a respeito deste estudo? Voltemos, então, à questão da vivência de hospitalização compreendida enquanto um processo. Em todas as pessoas que participaram dessa pesquisa foram nítidas as mudanças com o passar dos dias, tanto objetiva como subjetivamente. Embora não se neguem as mudanças, também ficou claro que em alguns momentos a fluidez dessas vivências não foi facilitada. O que há de tão importante nesse olhar para o processo? Acreditamos que essa maneira de olhar implica em deixar de lado a rigidez tão presente no cuidado hospitalar. Isso significa que é preciso também dar espaço para que essa fluidez ocorra ou, relembrando Rogers (1980/1983), para que a tendência atualizante se manifeste. Acompanhar a pessoa nessa busca pela melhora, a partir do referencial que ela tem de sua vida, já é uma maneira de oferecer um cuidado. Este estudo não teve a intenção de descrever como acontece o processo da hospitalização, mas sim, de perceber que, mesmo de maneira implícita, ele estava presente. Acreditamos que seja importante pensar mais sobre isso, já que não foi encontrado nenhum estudo que tratasse da hospitalização enquanto um processo.

Outro ponto relevante a se destacar é a qualidade subjetiva da internação. Como foi discutido, essa maneira de olhar nos aproxima do significado da vivência da pessoa hospitalizada. Nesse sentido, pensamos que seja importante a realização de pesquisas que levem em conta esse tipo de qualidade de internação, até porque não foram encontrados estudos com essa perspectiva, embora tenhamos encontrado pesquisas que se apóiem em aspectos objetivos (Gouvêa, Travassos \& Fernandes, 1997; Noronha, Machado \& Lima, 1996).

Por outro lado, a questão da qualidade também nos faz repensar aquilo que pode ser melhorado para promover o bem-estar dessa pessoa, não só do ponto de vista físico, mas de maneira geral, considerando a totalidade e a complexidade do ser humano. Estar atento a isso significa que não somente a condição psicológica do interno possa melhorar, mas sim, a pessoa como um todo, e isso inclui a dimensão física também.

Nesse sentido, cabe mencionar mais uma vez a importância de se rever o cuidado prestado nos hospitais. Essa atenção não necessariamente precisa ser exercida somente pelo psicólogo da instituição, mas pode ser oferecida por outros profissionais da saúde que, na maioria das vezes, têm mais contato com a pessoa hospitalizada. Isso não quer dizer que os profissionais tomem o lugar do psicólogo, mas acreditamos que eles possam promover uma atenção mais completa, que não se prenda somente ao corpo e à doença.

O cuidado, portanto, deve estar permeado nas atitudes dos profissionais em seu dia-a-dia, tanto numa conversa informal com o interno como também no momento delicado de realização de procedimentos. É certo que não há uma receita ou um manual de como se deve agir com as pessoas internadas, já que, estando em jogo a subjetividade das pessoas, é impossível prever o que poderá surgir. Apesar disso, ao longo desse estudo, foram propostas algumas atitudes que podem facilitar um diálogo mais genuíno e verdadeiro com essas pessoas (ou com qualquer outra).

\section{Referências}

Amatuzzi, M. M. (1995). Descrevendo processos pessoais. Estudos de Psicologia, 12, 65-79.

Amatuzzi, M. M. (2001). Por uma psicologia humana. Campinas: Alínea.

Amatuzzi, M. M. (2003). Pesquisa fenomenológica em psicologia. Em M. A. de T Bruns \& A. F. Holanda (Orgs.), Psicologia e pesquisa fenomenológica: Reflexões e perspectivas (pp.17-25). São Paulo: Alínea.

Benjamin, W. (1994). Obras escolhidas - magia e técnica, arte e política. São Paulo: Brasiliense. (Trabalho original publicado em 1937)

Bellato, R. (2001). A vivência da hospitalização pela pessoa doente. Tese de Doutorado, Universidade de São Paulo, Ribeirão Preto.

Buber, M. (1982). Do diálogo e do dialógico. São Paulo: Perspectiva.

Chaves, E. C. \& Ide, C. A. C. (1995). Singularidade dos sujeitos na vivência dos papéis sociais envolvidos na hospitalização. Revista da Escola de Enfermagem (USP), 29, 173-79.

Ferreira, A. B. de H. (2004). Novo dicionário Aurélio da língua portuguesa. Curitiba: Positivo.

Forghieri, Y. C. (2002). Psicologia fenomenológica-fundamentos, método e pesquisas. São Paulo: Pioneira Thomsom Learning.

Forghieri, Y. C. (2007). Aconselhamento terapêutico - origens, fundamentos e práticas. São Paulo: Pioneira Thomsom Learning.

Gouvêa, C. S. D. Travassos, C. \& Fernandes, C. (1997). Produção de serviços e qualidade da assistência hospitalar no Estado do Rio de Janeiro, Brasil - 1992 a 1995. Revista de Saúde Pública, 31, 6, 601-617.

Graças, E. M. das (1996). A experiência da hospitalização: uma abordagem fenomenológica. Tese de Doutorado, Escola de Enfermagem da USP, São Paulo.

Houaiss, A. \& Villar, M. de S. (2001). Dicionário Houaiss da língua portuguesa. Rio de Janeiro: Objetiva.

Merighi, M. A. B. (2002). Cuidado: enfermagem e fenomenologia. Em D. S. P. de Castro (Org.), Existência e saúde (pp. 153-170). São Bernardo do Campo: UMESP.

Merleau-Ponty, M. (1999). Fenomenologia da percepção (C. A. R. Moura, Trad.). São Paulo: Martins Fontes. (Trabalho original publicado em 1945)

Michaelis (2001). Dicionário prático de inglês. São Paulo: Editora Melhoramentos

Mucchielli, A. (1991). Les méthodes qualitatives. Paris: PUF. 
Noronha, M. F., Machado, C. V \& Lima, L. D. (1996). Proposta de indicadores e padrões para a avaliação de qualidade da atenção hospitalar: o caso da asma brônquica. Cadernos de Saúde Pública, 12 (2 suplemento), 43-58.

Palmieri, T. H. (2005). Plantão psicológico em hospital geral: um estudo fenomenológico. Dissertação de Mestrado, Pontifícia Universidade Católica de Campinas, Campinas.

Pokladek, D. D. \& Haddad, N. C. (2004). Mergulhar no mar da humanidade: uma reflexão fenomenológico-existencial na prática do profissional da saúde. Em D. D. Pokladek (Org.), $A$ fenomenologia do cuidar: prática dos horizontes vividos nas áreas da saúde, educacional e organizacional (pp. 261-270). São Paulo: Vetor.

Rogers, C. R. (1983). Um jeito de ser (M. C. M. Kupfer, H. Lebrão \& Y. S. Patto, Trads.). São Paulo: EPU. (Trabalho original publicado em 1980)

Rogers, C. R. (1997). Tornar-se pessoa (M. J. C. Ferreira e A. Lamparelli, Trad.) São Paulo: Martins Fontes. (Trabalho original publicado em 1961)

Rogers, C. R. (1977). Psicoterapia e relações humanas: teoria e prática da terapia não-diretiva, Vol. 1 (M. L. Bizzotto, Trad.). Belo Horizonte: Interlivros. (Trabalho original publicado em 1965)
Sant'Anna, D. (2000). Pacientes e passageiros. Interface Comunicação, Saúde e Educação, 4, 13-20.

Valle, E. R. M. \& Françoso, L. P. C. (1997). Psicologia e a enfermagem: a questão do adoecer. Revista Psicologia Argumento, 15, 61-70.

Van Den Berg, J. H. (1973). O paciente psiquiátrico - esboço de psicopatologia fenomenológica. São Paulo: Mestre-Jou, (Trabalho original publicado em 1955)

Toralles-Pereira, M. L, Sardenberg, T., Mendes, H. W. B. \& Oliveira, R. A. (2004). Comunicação em saúde: algumas reflexões a partir da percepção dos pacientes acamados em uma enfermaria. Ciência e Saúde Coletiva, 9, 1013-1022.

Recebido em 09.02.2007 Primeira decisão editorial em 24.07.2007 Versão final em 29.09.2007 Aceito em 01.02.2008 